\title{
Downscaling solar irradiance using DEM- based model in young volcanic islands with rugged topography
}

Miloud Bessafi ${ }^{\mathrm{a}}$, Vishwamitra Oree ${ }^{\mathrm{b}, ~}{ }^{*}$, Abdel Khoodaruth ${ }^{\mathrm{c}}$, Guillaume Jumaux ${ }^{\mathrm{d}}$, François Bonnardot ${ }^{\mathrm{d}}$, Patrick Jeanty ${ }^{\mathrm{a}}$, Mathieu Delsaut ${ }^{\mathrm{a}}$, Jean-Pierre Chabriat ${ }^{\mathrm{a}}$, Muhammad Zaid Dauhoo ${ }^{\mathrm{e}}$

\footnotetext{
a Laboratoire d'Energétique, d'Electronique et Procédés (LEEP), Université de la Réunion, 15 Avenue René Cassin, Sainte-Clotilde 97715, La Réunion, France ${ }^{\mathrm{b}}$ Electrical and Electronic Engineering Department, Faculty of Engineering, University of Mauritius, Mauritius

${ }^{c}$ Mechanical and Production Engineering Department, Faculty of Engineering, University of Mauritius, Mauritius

d Direction Interrégionale de la Réunion, Météo-France, France

e Department of Mathematics, Faculty of Science, University of Mauritius, Mauritius
}

\section{A B S T R A C T}

Many small island developing states are adopting solar photovoltaic technologies as a solution to curtail their overreliance on fossil fuels. Some of these islands are young and of volcanic origin, characterised by intricate topographic heterogeneity. Since they are mostly small, flat land is scarce and valuable. As a result, solar photovoltaic projects are usually developed at sites with complex terrain where frequent changes in elevation, slope and shadows cast by topographic features can significantly attenuate the amount of solar irradiance received. The existence of strong local solar radiation gradients on such islands implies that any solar resource assessment must be performed at a small enough spatial and temporal resolution in order to provide a reliable basis for investment decisions. Ground-based mea-surements of solar irradiance are accurate but are widely dispersed geographically. Although satellite-derived solar resource data have better spatial and temporal resolution than those recorded by radio-metric stations, they are less accurate. Moreover, their spatial resolution is still too large with respect to the small size of the islands. In this work, a downscaling methodology is used to derive monthly and annual average global solar irradiance maps at a resolution of $250 \mathrm{~m} \times 250 \mathrm{~m}$ using satellite hourly datasets, spanning over the period 1999 to 2015 and having a spatial resolution of $0.05^{\circ} \times 0.05^{\circ}$. The combined effects of horizon blocking and sky obstruction resulting from heterogeneous topography are considered by applying a binary blocking factor and sky view factor respectively. The downscaled maps are then refined by convolving them with ground-based measurements through a kriging procedure. The methodology is validated using leave-one-out kriging procedure and illustrated successfully with the case of Reunion Island, where strong local gradients of solar irradiance were easily distinguished in regions marked by uneven topographic features.

\section{Introduction}

In recent years, the cumulative capacity of solar photovoltaic (PV) installations worldwide has grown at a remarkable rate. The capacity addition of about $50 \mathrm{GW}$ in 2015 alone is nearly 10 times more than the total global installed capacity of solar PV in 2005 [1].

\footnotetext{
* Corresponding author. Electrical and Electronic Engineering Department, Faculty of Engineering, University of Mauritius 80837 Reduit, Mauritius

E-mail address: v.oree@uom.ac.mu (V. Oree).
}

A combination of factors has led to this rapid growth, the most prominent ones being technological developments, decline in costs and incentive regimes. The last two factors have led to an increasing number of stakeholders looking to exploit a profitable investment opportunity [2]. From a strictly economic perspective, the viability of a solar energy project hinges on its potential for power genera tion, which is largely dependent on the solar resource availability at the site. Therefore, it is crucial to have a comprehensive charac terisation of the solar resource at specific sites as well as its spatial distribution across the region in order to facilitate investment de cisions. Such high intensity measurements require costly 
radiometric networks at small spatial resolutions that necessitate regular maintenance and calibration. For all these reasons, ground based databases of solar radiation at high temporal resolution over long time periods is scarce $[3,4]$. Besides, in regions where they are available, the radiometric networks are often widely dispersed geographically. The presence of micro climates and dissimilar topographical features in these regions can lead to considerable differences in solar resource over short distances. In such cases, the ground based solar resource data does not provide a reliable basis for technology selection and investment decision making. Inter polation techniques that are commonly applied to derive spatial databases from ground measurements, such as spline functions, weighted average procedures and kriging, work reasonably well for flat terrains but the soundness of these approaches declines as the topography becomes more complex [5].

Data derived from satellite observations of the atmosphere have been widely applied as a cost effective alternative to ground based measurements. Satellites can provide solar resource data at a higher spatial resolution and usually closer to PV installation sites than the nearest ground based station. High resolution satellite data are used extensively in the research literature to estimate the solar resources of many countries all around the world [6-11]. While satellite based solar irradiance datasets account for the ef fect of clouds by applying established algorithms, they do not consider topographic effects. Changes in elevation, slope, surface orientation and shadowing by topographic features can produce strong local gradients in solar radiation [12]. Satellite based data sets are also more amenable to the integration of topographic ef fects due to their small temporal and spatial resolution. Since each satellite based solar irradiance data represents the mean value within the area covered by a pixel, information about the variability of solar irradiance within this area is not provided. Elevation and surface orientation can vary significantly within one pixel in re gions of complex topography.

The case of young volcanic islands, which present many such characteristics, is interesting. They are usually small, with areas less than $2500 \mathrm{~km}^{2}$. As a result, their satellite based solar irradiance maps are intrinsically represented by a limited number of pixels. Furthermore, many young volcanic islands have very complex to pographies, marked by steep cliff rising out of the sea and large caldera like valleys, known as cirques, with very narrow outlets to the sea through deep gorges [13]. The absence of natural resources in these islands has led to a heavy dependence on fossil fuels for their energy requirements. However, many of them have pledged to overcome their overreliance on fossil fuels by exploiting the abundant solar energy to which they have access. One such island is Reunion, located in the South West of the Indian Ocean, where the installed solar PV capacity has increased by 44\% from 2011 to 2015 [14]. The extremely varied and steep topographical features on the island give rise to many micro climates such that there are often considerable differences in solar resource over short distances that are not detected due to the wide geographical dispersion of ground measurement stations [15]. Given that flat lands are extremely precious resources on the island, solar PV projects are usually implemented in rugged terrains. Thus, determining the solar irra diance at small spatial and temporal resolution is a very important issue in young volcanic islands striving to deploy solar PV on a large scale. Yet, studies have not been performed for these particular cases.

Several models were developed to factor topographic effects into satellite based solar irradiation data, such as SolarAnalyst [16] and SRAD [17]. They are based on a digital elevation model (DEM) which provides elevation and surface orientation information. Other common inputs include simplified atmospheric conditions represented by regional meso scaled parameters which induce inaccuracies in the models and therefore limit their use for oper ational modelling [18]. More specifically, these models preclude disaggregation of external solar maps provided by other services [19]. An appropriate approach to bring the resolution of solar irradiance maps to a DEM scale while modelling topographic effects would require devising methodologies to disaggregate solar irra diance into its major components and applying the effects of terrain complexity on them individually. However, the computations involved in this approach can present important performance limitations [19].

Bosch et al. [20] used a modified Heliostat 2 model to consider the effects of horizon elevation on diffuse radiation, sunrise and sunset times together with the influence of snow cover on daily solar irradiance. Validation of the model against ground measure ments showed that these corrective measures decreased the root mean square error (RMSE) of the satellite estimates by about $5 \%$ on average. The accuracy of existing models was further enhanced with varying degrees of success by combining DEMs with explicit disaggregation techniques of satellite derived radiation maps. Ruiz Arias et al. [18] disaggregated Meteosat derived maps from a resolution of about $5 \mathrm{~km}$ to a DEM resolution of $90 \mathrm{~m}$. This was followed by the decomposition of global irradiance into its direct, diffuse circumsolar and diffuse isotropic components using statis tical models, and the application of corrections due to terrain elevation and sky view fraction. Results indicated that the method strongly reduced the mean bias of the estimates for clear and cloudy days. Haurant et al. [21] also adopted a spatial disaggrega tion approach to downscale irradiance maps for Corsica from a $10 \mathrm{~km}$ satellite resolution to a $90 \mathrm{~m}$ DEM grid. Elevation effects were considered by decomposing global irradiance into its diffuse and beam components and applying surrounding horizon in fluences to them. Finally, the components were re aggregated to get the shaded global irradiance. The authors computed errors introduced at the various stages of the procedure. It was observed that the selected global irradiance decomposition function gener ated a major error which was subsequently attenuated during the re aggregation stage. Nevertheless, the overall process improved the RMSE of the satellite estimates up to $0.5 \%$, with the most meaningful upgrade achieved in high relief and rugged terrains.

In this paper, we propose a fast modified downscaling meth odology which overcomes the performance limitations imposed by complex computations of horizon angle and sky obstruction at each DEM pixel. Moreover, the proposed methodology is convenient as its input data requirements, consisting of long term hourly means of global irradiance data and a DEM of the region, are readily available. In addition, the reliability of the resulting downscaled solar irradiance maps is enhanced by applying a stochastic inter polation procedure through kriging with ground measurements. Finally, this study has been able to more accurately validate the proposed methodology by making use of a larger quantity of ground stations over a smaller area compared to much less denser radiometric networks used for validation in previous studies. Sec tion 2 describes the studied region, a comparative analysis of the solar irradiance values derived from the EUMETSAT Satellite Application Facility on Climate Monitoring (CMSAF) with respect to the ground measurements obtained from the existing radiometric. Section 3 presents the methodology adopted to take into account the effects of shadowing and sky obstruction. Section 4 provides the resulting downscaled monthly and yearly solar irradiance maps of Reunion Island. It also discusses the performance of the proposed methodology compared to the initial satellite derived irradiance maps and ground measurements. 


\section{Materials and methods}

\subsection{Location and its characteristics}

Reunion is a small island of just $2512 \mathrm{~km}^{2}$ and is a French overseas department. There are more than 300 inhabitants per $\mathrm{km}^{2}$ with a majority of the population located close to the coast of the island due to the presence of several zones of complex topography, many of which are remote and difficult to access. Reunion has a typical tropical climate, with a hot and humid summer season from November to April and a dry and cool winter season from May to October. The island receives a lot of sunshine throughout the year. Fig. 1 depicts the monthly average of daylength at Gillot, located in the North of the island. It can be observed that up to $13 \mathrm{~h}$ of daylight are obtained during peak summer months while this number de creases to about $11 \mathrm{~h}$ during peak winter months. Nevertheless, due to cloud covers and topography pattern, the monthly mean of bright sunshine hours during the day recorded at the same location is roughly half the amount of daylight hours and constant throughout the year [22].

The topography of Reunion Island is characterised by two coa lescent volcanic massifs: the dormant Piton des Neiges (about $3070 \mathrm{~m}$ above sea level) in the North West of the island and the highly active Piton de La Fournaise (about $2632 \mathrm{~m}$ above sea level) in the South East [23]. The collapses of Piton des Neiges massif are revealed by deep valleys and three central major cirques of Mafate, Salazie, and Cilaos [23]. On the other hand, a range of calderas and arcuate valley rims outline the Piton de la Fournaise. These prom inent geological features can be clearly distinguished in Fig. 2. The two volcanic massifs are connected by a plateau situated at about $1500 \mathrm{~m}$ above sea level.

In the 1980s, the island met all of its electricity requirements through renewable hydro power but as the demand escalated over the years, the island became gradually dependent on imported fossil fuels [24]. In 2008, 64\% of the country's power was generated by fossil fuels. To curb this overreliance on fossil fuels and its associated economic and environmental issues, Reunion Island adopted a plan to achieve full energy autonomy by 2030 [24]. To this end, the abundant local renewable energy resources would be exploited, particularly solar energy. In this context, various initia tives have been taken resulting in an installed solar PV capacity of $167.8 \mathrm{MW}$, representing $8.5 \%$ of the total electricity mix [14]. Nevertheless, characterisation of its solar resource is required to drive solar projects.

\subsection{Existing radiometric network}

For this purpose, the island has invested heavily in a radiometric network of 32 stations to measure the solar irradiance at various

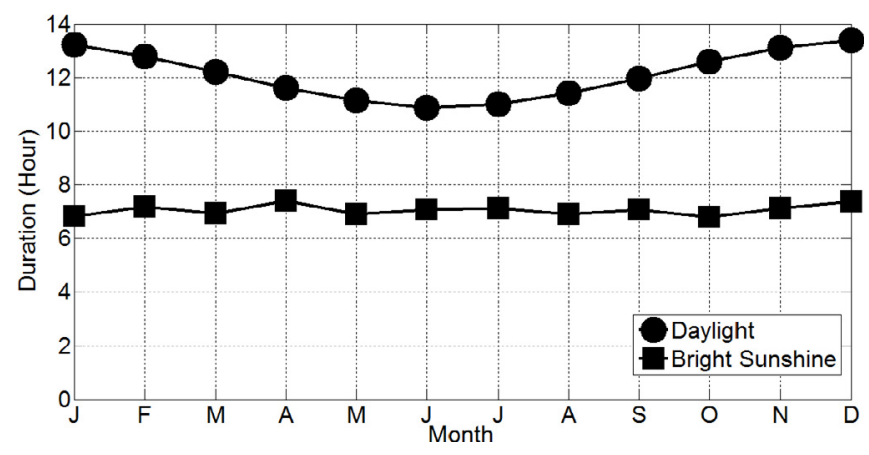

Fig. 1. Average monthly hours of daylight and bright sunshine in Reunion Island.

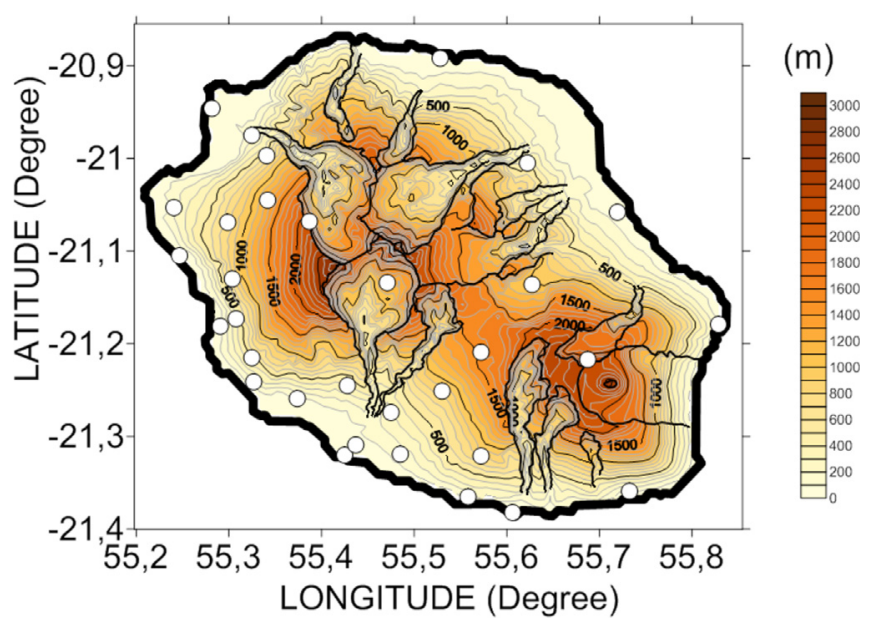

Fig. 2. Locations of the 32 radiometric stations (indicated by white dots) on a $250 \mathrm{~m} \times 250 \mathrm{~m}$ DEM of Reunion Island.

locations. 16 of the stations are operated by Meteo France, the French meteorological organisation, and the rest are under the control of the French agricultural research and international cooperation organisation (CIRAD). Twenty stations are equipped with CM6B pyranometers, eight with CM5, two with CM11 and with CMP6, all from Kipp and Zonen. The equipment is calibrated every two years while the readings are monitored on a daily basis. Most of the sites of the stations are categorised as either Class 1 or 2 , based on the site classification defined by Meteo France which ranges from 1 to 5 , where Class 1 refers to sites that strictly follow the World Meteorological Organization recommendations while Class 5 pertains to sites where nearby obstacles create an inap propriate environment for meteorological measurement.

Fig. 2 shows the locations of the 32 stations of this network on a DEM of Reunion Island. It is noted that the stations do not cover all the morphologically heterogeneous environments of the island due to the rugged and mountainous relief. In particular, radiometric stations are located principally near the coastal regions with very few in the neighbourhood of the Piton des Neiges and Piton de La Fournaise massifs, where the topography is most complex. In addition, stations are mostly situated in the southern half of the island. Consequently, they do not capture the spatial and temporal variability of solar irradiance across all regions. Table 1 highlights the discrepancies between the statistics of the station locations in the radiometric network and actual terrain elevation of Reunion Island. It can be deduced that all stations are situated within an altitude of $2245 \mathrm{~m}$ while the island culminates at a height of about $3008 \mathrm{~m}$. The first and third quartile data further show that half of the stations are found between altitudes of $60 \mathrm{~m}$ and $800 \mathrm{~m}$. Moreover, the mean and median altitudes of stations indicate their locations are not representative of the wide range of topographic

Table 1

Comparison of statistics of station locations and digital elevation model of Reunion Island.

\begin{tabular}{lll}
\hline & DEM & Solar radiation site \\
\hline Minimum Elevation (m) & 0 & 5 \\
Mean Elevation $(\mathrm{m})$ & 863 & 522 \\
Median Elevation $(\mathrm{m})$ & 766 & 248 \\
Maximum Elevation $(\mathrm{m})$ & 3008 & 2245 \\
Standard Elevation $(\mathrm{m})$ & 657 & 610 \\
$1^{\text {st }}$ quartile $(\mathrm{m})$ & 276 & 59 \\
$3^{\text {rd }}$ quartile $(\mathrm{m})$ & 1358 & 801 \\
\hline
\end{tabular}


conditions prevailing on the island. In these circumstances, ground based solar resource measurements do not provide a reliable basis for solar PV investment decision making.

The mean cumulative monthly global horizontal irradiance (GHI) for Reunion Island, based on hourly data obtained Météo France for the period 01 January 2010 to 31 December 2015 at the 32 stations, is shown in Fig. 3. It can be inferred that not only the GHI varies considerably throughout the year but also that there exists a significant spatial variability in GHI during any specific month. The largest differences in GHI values are observed during summer months. For example, the minimum and maximum values of GHI recorded by the 32 stations are 105 and $218 \mathrm{~kW} / \mathrm{m}^{2}$ respectively in December.

This high range of variability from one location to another is mainly due to the dynamic forcing by complex mountainous terrain which can trigger local cloud cover. In addition, favourable condi tions of cloud formation over the island are mainly driven by local sea/land breeze and katabatic/anabatic, large scale trade wind flow. In order to compare the variability between stations independently to their mean, the coefficient of variation (CV) parameter for each station was computed (i.e. standard deviation divided by the mean). Fig. 4 displays the measure of the relative GHI's variability throughout the year. It is noted that the highest variability of approximately $20 \%$ takes place in the south coast area facing to the trade winds flow, along the remaining coast and inland. Further more, the lowest variability of around 10\% occurs over the mid altitude of northwest area which is related to the persistent over cast clouds within the windward flow.

\subsection{Satellite datasets}

Many solar resource databases derived from satellite images are available, either free or as commercial products [25]. The main differences among them relate to their input data, spatial resolu tion, models used to compute the solar parameters as well as the time period of records and their time resolution [26]. This study is based on the solar radiation database from CMSAF as it generates long term climate data records spanning over 16 years (1999-2015 with 2006 missing) and with a high spatial resolution of $0.05^{\circ}$, corresponding to about $5 \mathrm{~km}$ at the Equator [27]. This climatic dataset is derived from the first and second generation Meteosat satellites and provides information on solar surface irradiance, direct irradiance and effective cloud albedo (CAL) as hourly aver ages. Following validation of CM SAF datasets against standardised ground measurements, it was reported that their mean absolute deviation fulfils the optimal accuracy requirement of $8 \mathrm{~W} / \mathrm{m}^{2}$ while $90 \%$ of the monthly average data meet the target accuracy [25].

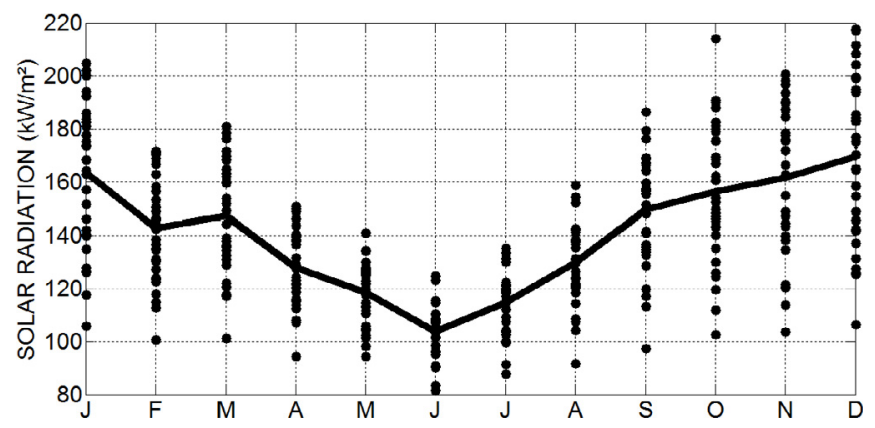

Fig. 3. Average monthly GHI solar radiation observed at the 32 stations network over Reunion for the period 2010 2015. The solid line represents the monthly trend of the average GHI over the 32 stations.
2.4Comparison of satellite dataset with ground based solar radiation measurements

While solar irradiance estimations based on satellite datasets have been reported to be superior than those obtained from interpolation methods applied to sparse ground measurements [28], it is interesting to compare the GHI data for Reunion Island derived from the CMSAF with the ground measurements. Since the satellite provides data in a $5 \mathrm{~km}$ resolution grid, the measurement by each radiometric station was compared with GHI data from the grid point closest to its location. Fig. 5 depicts the monthly relative difference between the satellite based GHI data, $\mathrm{GHI}_{\mathrm{CMSAF}}$, and the ground measurement at the 32 stations of the radiometric network. The red and blue dots indicate that satellite observations over estimate and underestimate, respectively, the solar irradiance with respect to the ground measurements. The numbers within each dot denote the relative difference, $D_{r}$, computed using Equation (1) where $\mathrm{GHI}_{\mathrm{m}}$ is the recorded $\mathrm{GHI}$ value at the ground station.

$$
D_{r} \quad \frac{G H I_{C M S A F} \quad G H I_{m}}{G H I_{m}} \times 100 \%
$$

It can be observed from Fig. 5 that on average, the relative dif ference is of the order of $10 \%$. However, the divergence is more prominent at some stations. In particular, the CMSAF based values of solar irradiance in the North West region of the island are significantly higher than the actual measurements, up to $66 \%$ dur ing the month of October at the Petite France station. This can be attributed to the fact that this region is frequently overcast due to clouds overflowing from the cirque of Mafate during the day, thereby attenuating the insolation. Another big deviation is observed in the South East region of Bellecombe, situated near the latest caldera created by the active Piton de La Fournaise. This station has the highest altitude among all the 32 stations, at a height of $2245 \mathrm{~m}$ above sea level. Here, the CMSAF dataset un derestimates the solar irradiance, up to $35 \%$ during the month of September. The Bellecombe station is situated above the atmo spheric boundary layer and is therefore exposed to drier air and fewer clouds. Yet, given that this region is marked with steep slopes, the neighbouring areas can rapidly be located under the boundary layer. The resulting higher cloud cover causes the dif ference to decrease noticeably at the closest two stations to $20 \%$ and $9 \%$ in September. Finally, a major positive deviation, varying be tween 19\% and 33\% during the year, is noted on the eastern coast of Sainte Rose. High cliffs rising suddenly from the sea are distinctive features along this coast. The incoming air mass is subjected to an orographic lift as it passes over the cliffs, followed by an adiabatic cooling due to the sudden increase in altitude. As a result, clouds develop on a regular basis in this area.

\subsection{Effect of topography on solar irradiance}

In theory, incident solar radiation on a PV panel placed should be equal to the total solar flux available from the hemispheric sky dome above that panel, that is, the entire sky from horizon to zenith, and in all azimuthal directions. However, this is applicable to flat terrains only. In practice, when the panel is placed in the neighbourhood of an elevated horizon, the amount of solar irradi ance incident on the panel is attenuated. A DEM, which represents topography by a grid of elevation points, is used in this study to quantify this attenuation. At every point in the grid, the elevation, slope and surface orientation may cast varying extents of shadows and shades on the panel. In order to account for these effects, the diffuse horizontal irradiation (DHI) and direct normal irradiation (DNI) that would have been incident on a panel located at that 


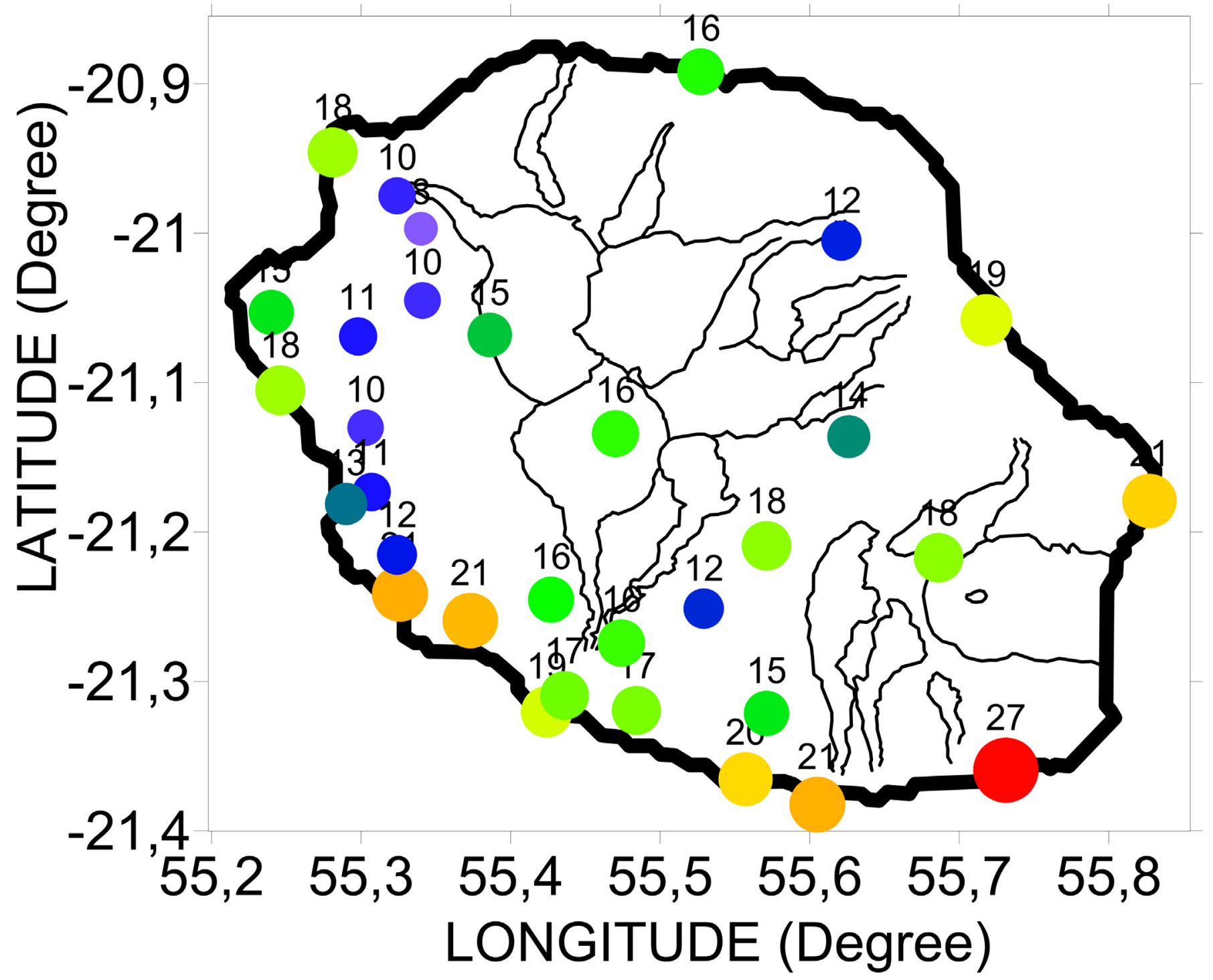

Fig. 4. Coefficient of variation (CV) parameter observed at the 32 stations network over Reunion Island during the period 20102015.

specific point assuming a flat terrain must be adjusted accordingly. For example, if a PV panel has an elevated horizon due to its loca tion in the vicinity of a mountain, the entire panel will be in shadow during the time when the sun is below the horizon. In this case, the output of the panel will be due to the DHI only as DNI will be zero. In general, if at a point, the solar zenith angle is greater than the zenith angle to the horizon, then that point is in shadow [12]. Fig. 6 illustrates how the topography modulates the cumulative hourly beam horizontal irradiation (BHI) during one year for Reunion Is land. It can be clearly observed that the cirques are much less exposed to direct irradiation due to shadowing.

In addition, a portion of the overlying hemispheric sky dome can be blocked by the nearby terrain, thereby reducing the amount of diffuse irradiance from the sky [12]. One important parameter that gives an idea on extent of sky obstruction is the sky view factor. The latter is the ratio of the diffuse sky radiation received by a surface to that which would be received by the same surface if it were completely exposed to the sky. Its value varies between 0 when the sky is totally obstructed, and 1 when a complete view of the sky hemisphere is observed above the horizon [29].

\section{Methodology}

The downscaling methodology used in this study was adapted from Antonanzas Torres et al. [30] and modified to enhance its overall reliability. The fundamental processes involved are illus trated in Fig. 7. The proposed model specifically addresses two major limitations of the methodology presented by Antonanzas Torres et al. [30]. Firstly, this study uses an extensive radiometric network with high spatial resolution, corresponding to about one station per $78 \mathrm{~km}^{2}$ of land area as opposed to one station per $850 \mathrm{~km}^{2}$ in the other case. Consequently, the ground based dataset is able to offer a much better representation of the rich spatial and temporal variability of solar resources caused by the very complex topography. Thus, when spatial interpolation of the downscaled maps is performed with ground based measurements, the accuracy of the resulting maps is significantly improved. Secondly, a reliable validation step has been integrated in the methodology to assess the performance of the final downscaled maps using leave one out cross validation technique. The latter involves leaving out one ground station as input and performing the kriging process using the remaining 31 stations. This procedure is repeated for each 

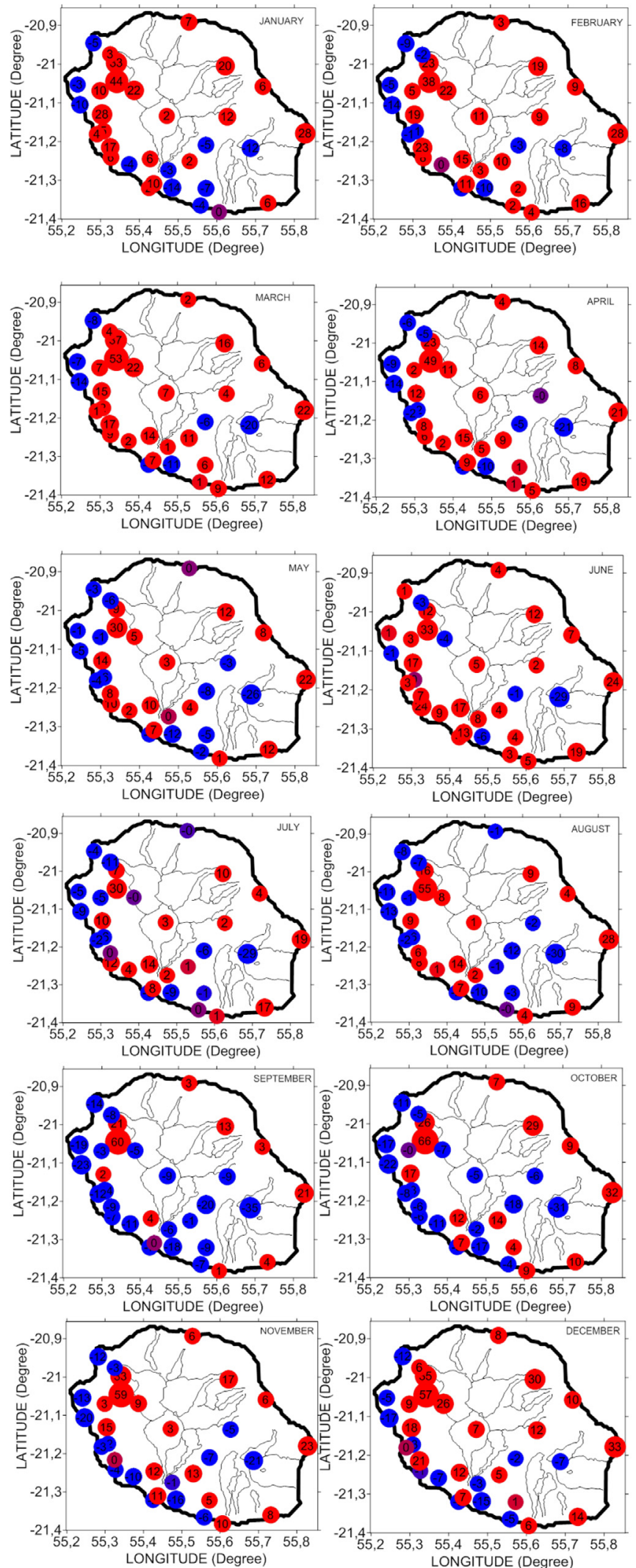

Fig. 5. Percentage relative difference between CMSAF-derived GHI and ground measurements on a monthly basis (Red and blue dots with associated numbers indicate the percentage overestimation and underestimation, respectively, of CMSAF-derived GHI with respect to the ground measurements).

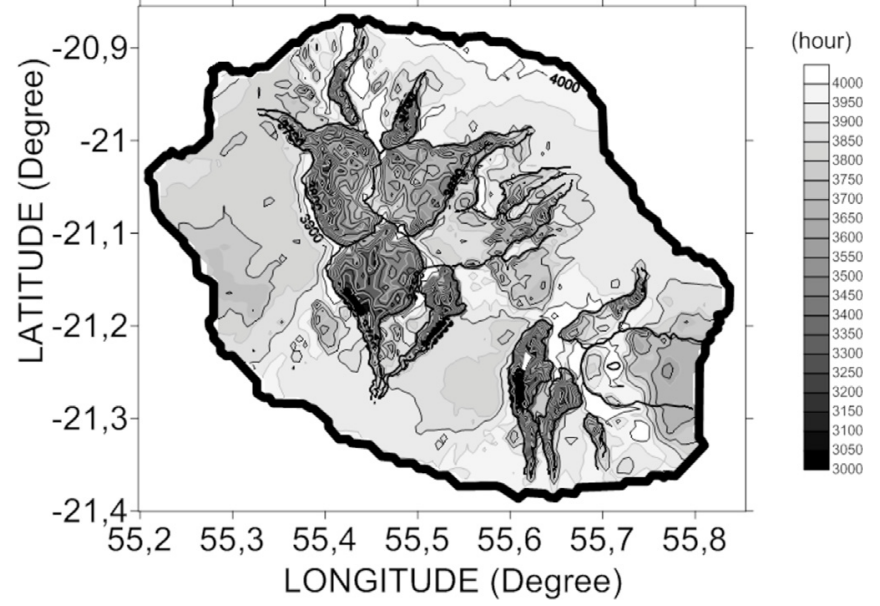

Fig. 6. Cumulative hourly beam horizontal irradiation through one year for Reunion Island.

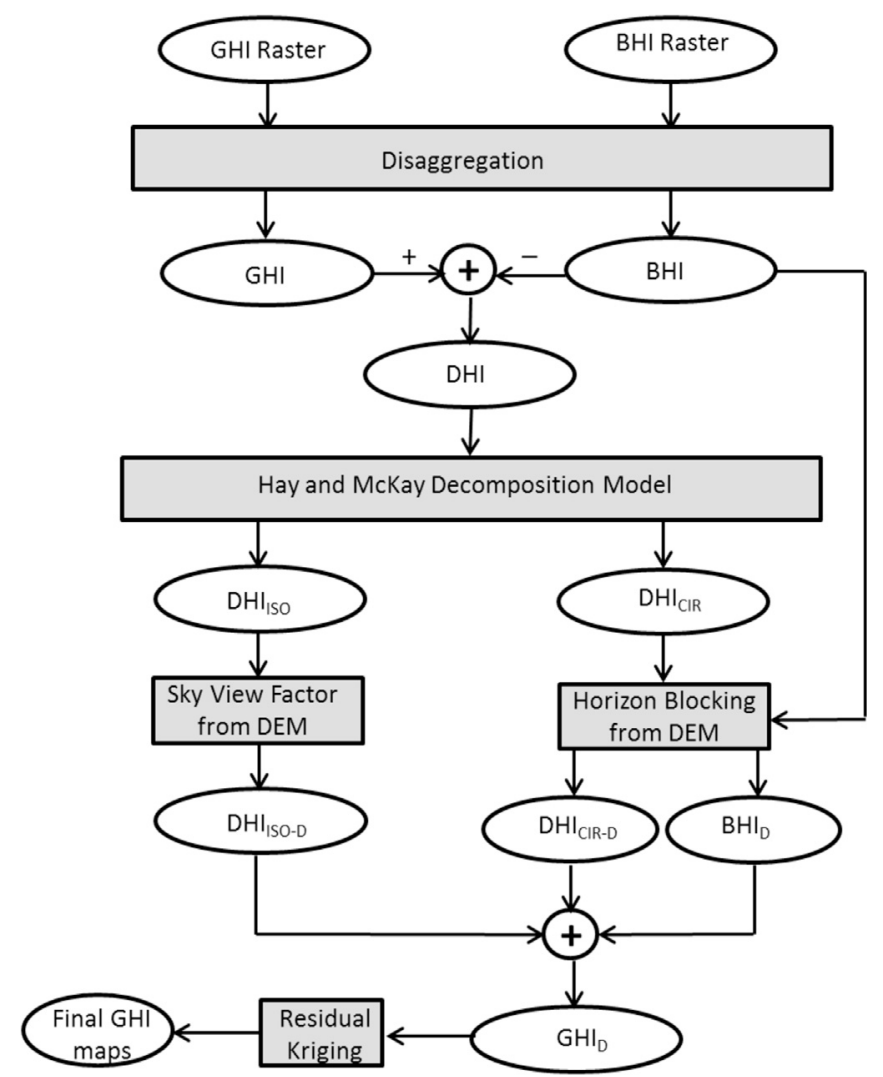

Fig. 7. Steps involved in downscaling methodology (adapted from Antonanzas-Torres et al. [30]).

ground station and for each month of the year. Every time, the interpolated value is compared with the measured value at the removed station and the accuracy is determined on a monthly basis by computing the RMSE.

The basic datasets for this study consist of hourly means of GHI and $\mathrm{BHI}$ for the period 1983 to 2005 in the form of raster data. The spatial resolution of the rasters is enhanced from $0.05^{\circ} \times 0.05^{\circ}$ of CMSAF SARAE to $250 \mathrm{~m} \times 250 \mathrm{~m}$ of the DEM by a disaggregation function. Subsequently, the disaggregated DHI data is derived by subtracting the disaggregated $\mathrm{BHI}$ from the disaggregated $\mathrm{GHI}$. 


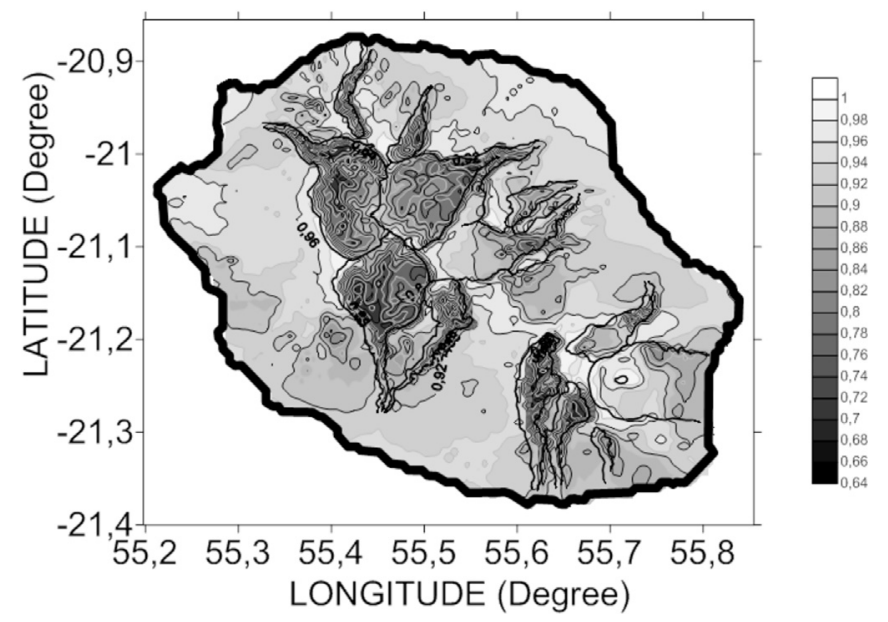

Fig. 8. Sky View Factor map of Reunion Island at $250 \mathrm{~m} \times 250 \mathrm{~m}$ resolution.

Next, DHI is decomposed into components emanating from various portions of the sky. For this purpose, some assumptions are made to simplify the highly variable nature of diffuse irradiance over the unobstructed portion of the sky hemisphere depending on the relative position of clouds and sun. Using the Hay and McKay model [31], DHI is divided in two components: an isotropic diffuse component $\left(\mathrm{DHI}_{\mathrm{ISO}}\right)$ resulting from the assumption that irradiance from the sky dome is uniform, and a circumsolar component $\left(\mathrm{DHI}_{\mathrm{CIR}}\right)$ coming from the sun's region to account for the scattering processes by the atmosphere's components. These two compo nents are weighted according to an anisotropic index, $\mathrm{k}_{1}$ repre senting the ratio of the beam irradiance to the extraterrestrial global solar irradiance on the horizontal plane. It quantifies the portion of diffuse radiation that is treated as circumsolar with the remaining portion assumed to be isotropic. Its value depends on the location and on the state of the atmosphere at that specific location [32]. Thus, high $\mathrm{k}_{1}$ values indicate clear sky atmospheres, while low $\mathrm{k}_{1}$ values are typical in overcast atmospheres or those with a high aerosol density. Equations (2)-(4) summarise the DHI decomposition model [31]:

$D H I \quad D H I_{I S O}+D H I_{C I R}$

$\mathrm{DHI}_{I S O} \quad\left(\begin{array}{ll}1 & k_{1}\end{array}\right) \cdot \mathrm{DHI}$

$\mathrm{DHI}_{\mathrm{CIR}} \quad k_{1} \cdot \mathrm{DHI}$

One of the major assumptions of the Hay and McKay model is

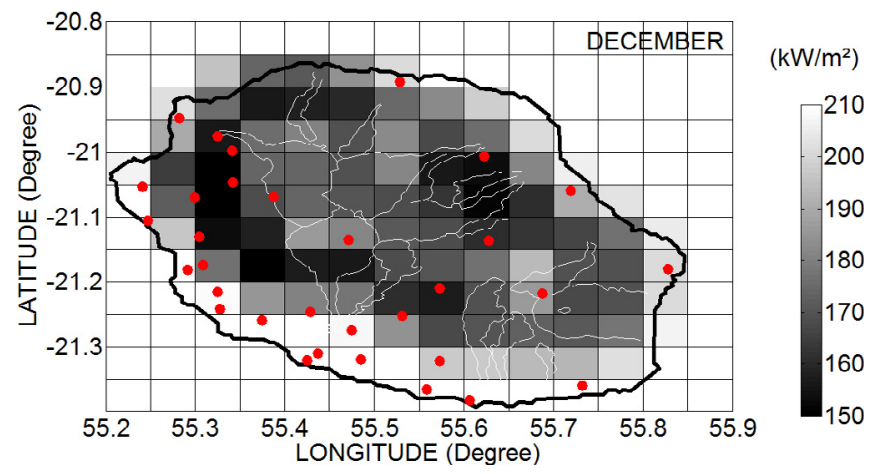

Fig. 9. Cumulative GHI for December in Reunion Island at $0.05^{\circ} \times 0.05^{\circ}$ resolution. that both the isotropic and circumsolar components form a linear combination based on the transmissivity for the direct radiation [31]. In addition, the anisotropic index $\mathrm{k}_{1}$ has been shown to vary a lot for a highly overcast sky while it is assumed to be zero here [31]. Nevertheless, Hay demonstrated that these deviations have a negligible impact on the performance of the anisotropic model [33]. Since DHI ISo is diffuse irradiance coming homogeneously from the sky, it should be downscaled by the sky view factor to consider only the unobstructed sky portion. The sky view factor (SVF) at each
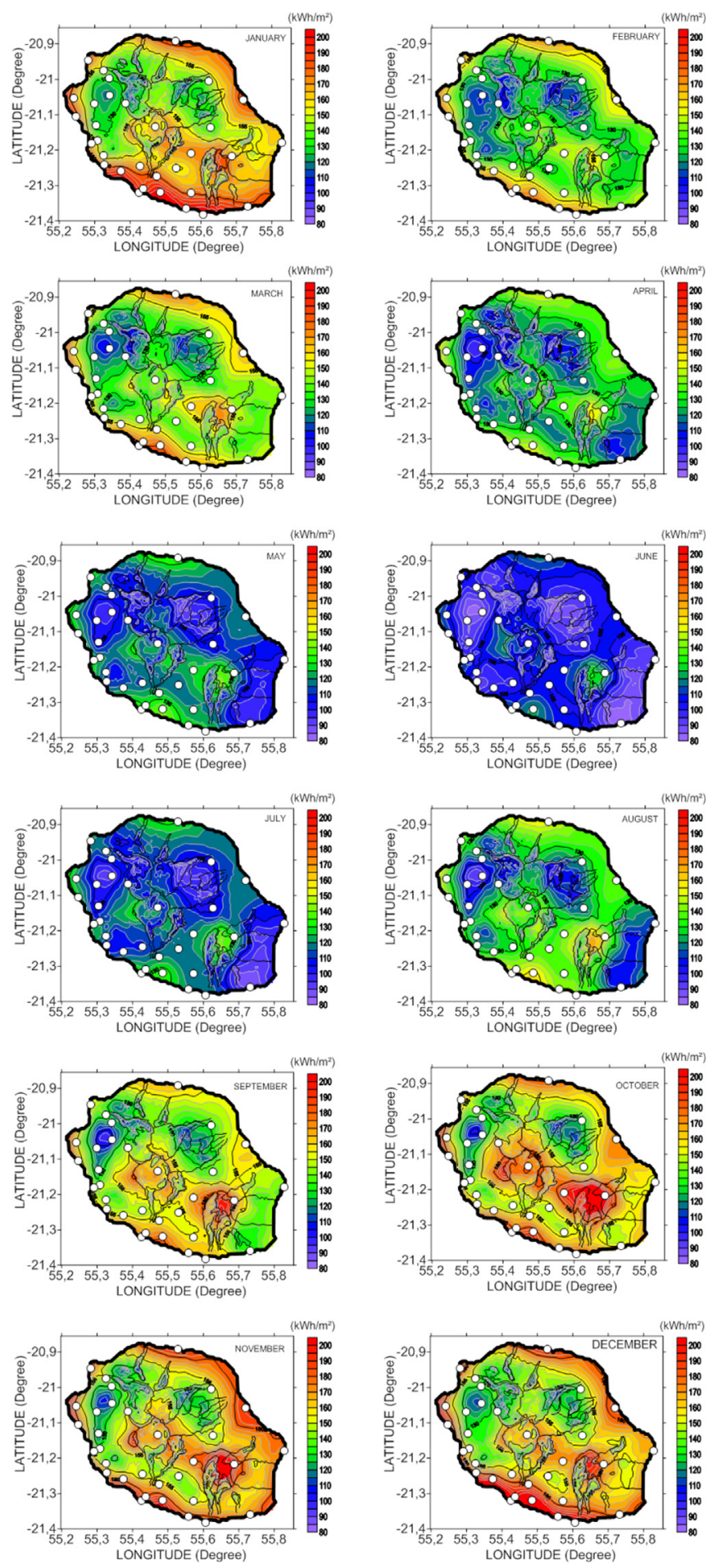

Fig. 10. Downscaled cumulative GHI maps for the months of January to December. 

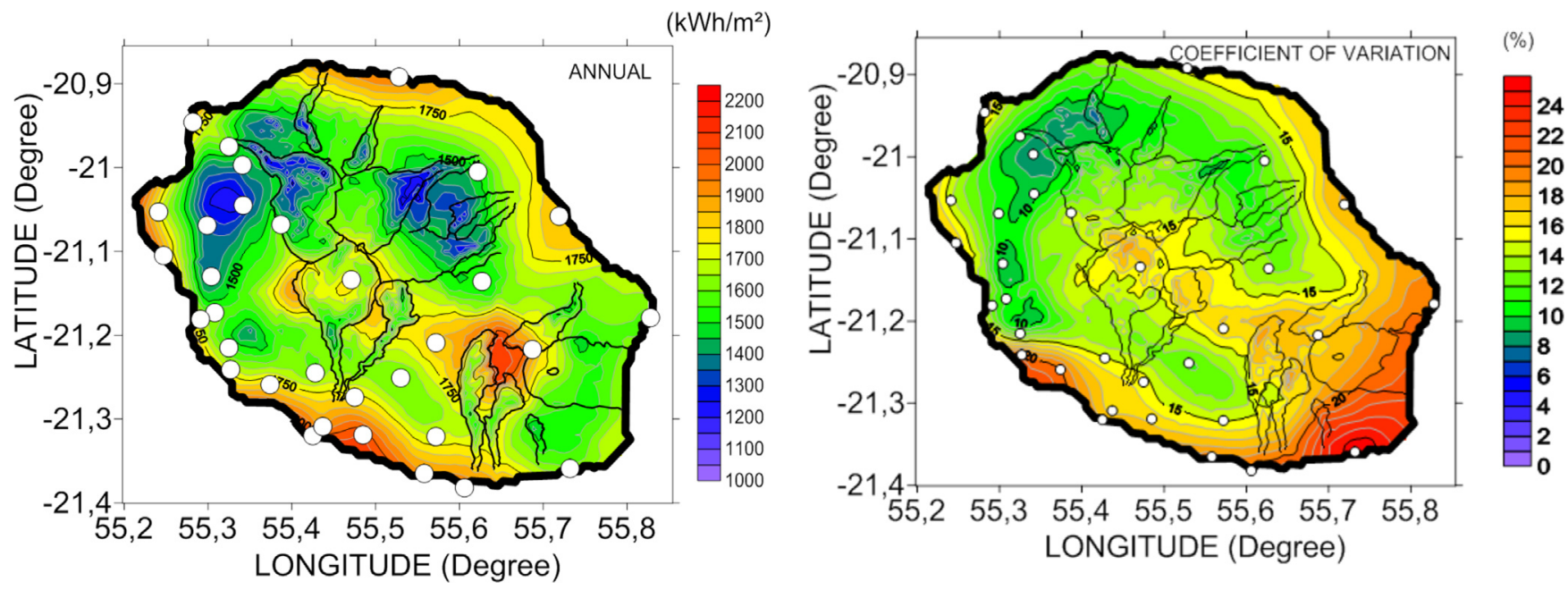

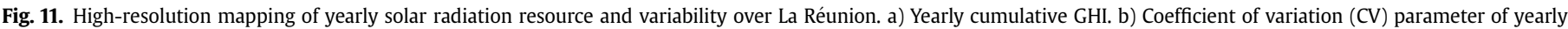
cumulative GHI.

pixel in the DEM is computed by considering 360 vectors, each separated by $1^{\circ}$, and evaluating the maximum elevation angle of the relief horizon, $\Upsilon_{\mathrm{i}}$, over $20 \mathrm{~km}$ in each vector using Equation (5) [34].

SVF $1 \frac{1}{360} \sum_{i=1}^{360} \sin \gamma_{i}$

The downscaled isotropic diffuse radiation, $\mathrm{DHI}_{\mathrm{ISO}-\mathrm{D}}$ is then obtained by the product of DHIISo and SVF.

On the other hand, horizon blocking is applied to $\mathrm{DHI}_{\mathrm{CIR}}$ and $\mathrm{BHI}$ to allow for shadowing caused by elevated horizons. At each pixel of the DEM, the maximum horizon angle is split into 24 intervals of $15^{\circ}$ each. During each hour, if the maximum horizon angle is found to exceed the solar altitude angle, it is assumed that both $\mathrm{BHI}$ and $\mathrm{DHI}_{\mathrm{CIR}}$ are completely blocked ( $\mathrm{HB} \quad 0$ ). Otherwise, there is no horizon blocking ( $\mathrm{HB} 1$ 1). In other words, the $\mathrm{DHI}_{\mathrm{CIR}}$ and $\mathrm{BHI}$ are multiplied by the binary parameter $\mathrm{HB}$ to obtain their downscaled values, $\mathrm{DHI}_{\mathrm{CIR}-\mathrm{D}}$ and $\mathrm{BHI}_{\mathrm{D}}$ respectively. It must also be noted that horizon blocking happens mostly at small solar altitude angles, during the hours following sunrise and preceding sunset. Following these computations, the downscaled GHI is then obtained by Equation (6).

$G H I_{D} \quad D H I_{I S O-D}+D H I_{C I R-D}+B H I_{D}$

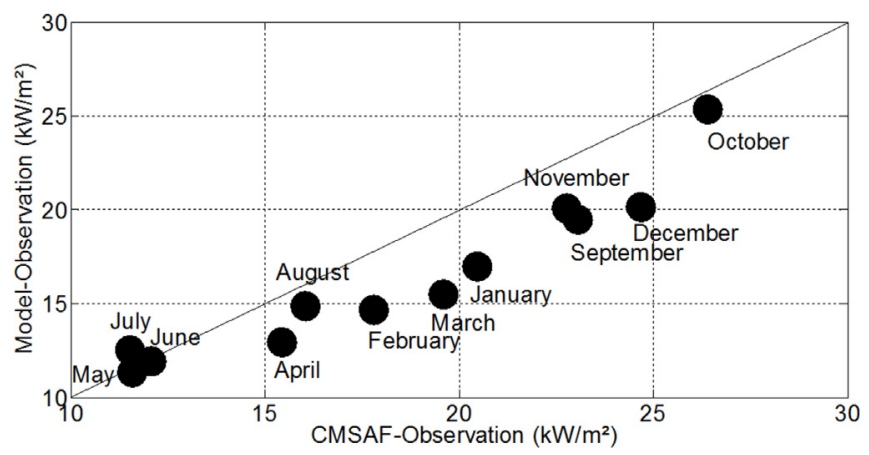

Fig. 12. Comparison of RMSE for each month between downscaled GHI obtained after the leave-one-out kriging process and the satellite-based GHI data with respect to ground measurements.
The previous steps lead to low spatial resolution, monthly and annual maps of GHI that consider the combined effects of horizon blocking and sky obstruction due to topographic features. Never theless, as seen in Section 2.4, there are inherent discrepancies between the maps derived from CMSAF datasets and ground measurements. In this context, the accuracy of the maps can be further enhanced by using a spatial interpolation scheme that ac counts for the error characteristics of these maps with respect to the ground measurements. To this end, the difference between the data recorded by the 32 radiometric stations and the GHI value in the corresponding pixel in each of the downscaled maps is computed. This difference or error in existing pixels is then inter polated by the ordinary kriging method [35] to generate a map of residual errors for all pixels in a $250 \mathrm{~m} \times 250 \mathrm{~m}$ resolution. The residual error map represents the corrections that must be applied at each pixel of the corresponding downscaled GHI. The final GHI estimate is obtained by combining the residual error map with the downscaled GHI map over the kriging grid [36].

\section{Results and discussion}

Fig. 8 indicates that the sky view factor varies substantially across Reunion Island, from 1 at very few locations to 0.64 near some cirques. Therefore, the full hemispheric sky dome can rarely be seen on the island, and a meaningful part is obstructed by the terrain at most locations, thereby attenuating the DHI ISO. Fig. 9 shows that the distribution of the cumulative GHI for the sum mer month of December, based exclusively on CM SAF data, varies in the range of $150-210 \mathrm{~kW} / \mathrm{m}^{2}$. The red dots indicate the locations of the 32 stations in the radiometric network. Although it can be noted that the resolution is rather coarse with pixel grid of only $14 \times 12$, a general trend in spatial variability of the GHI can be distinguished.

Fig. 10 shows the downscaled cumulative GHI maps for the months of January to December for Reunion Island after application of kriging. It can be clearly seen that the resolution of the maps was enhanced substantially as compared to Fig. 9. Most importantly, a wide dispersion of solar irradiance values is obtained over short distances. This effect can be clearly observed in the region of the two volcanic massifs. For example, GHI varies between 120 and $200 \mathrm{~kW} / \mathrm{m}^{2}$ around the Piton des Neiges massif in January.

Fig. 11a and Fig. 11b summarise the high resolution mapping of 

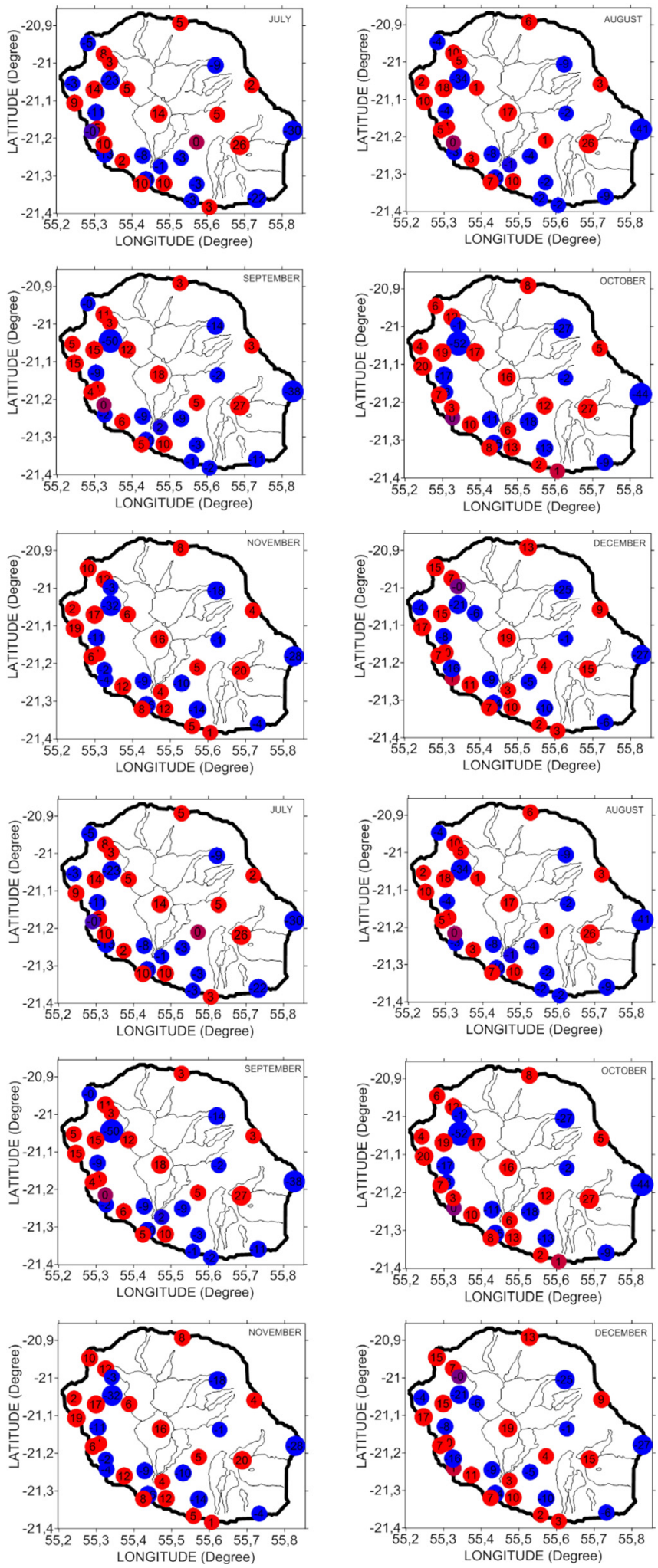

Fig. 13. Percentage relative difference between downscaled GHI after leave-one-out kriging and ground measurements on a monthly basis (Red and blue dots with associated numbers indicate the percentage overestimation and underestimation, respectively, of downscaled GHI after leave-one-out kriging with respect to the ground measurements).
Table 2

Comparison of percentage errors obtained for each month between maps obtained from proposed model and CM-SAF database with respect to ground measurements.

\begin{tabular}{llllll}
\hline \multirow{2}{*}{ Month } & \multicolumn{2}{l}{ Model } & & \multicolumn{2}{l}{ CMSAF } \\
\cline { 2 - 3 } \cline { 5 - 6 } & RMSE (\%) & MBE (\%) & & RMSE (\%) & MBE (\%) \\
\hline January & 10.5 & 0.5 & & 13.2 & 6.4 \\
February & 10.2 & 0.6 & & 11.9 & 7.1 \\
March & 10.6 & 0.7 & & 13.9 & 6.8 \\
April & 10.5 & 0.2 & & 12.6 & 4.8 \\
May & 10.0 & -0.3 & & 10.1 & 2.4 \\
June & 11.9 & -1.1 & & 10.7 & 6.1 \\
July & 11.4 & -0.4 & & 10.3 & 1.6 \\
August & 12.5 & -0.2 & & 13.9 & 2.2 \\
September & 14.4 & -0.4 & & 16.2 & -3.5 \\
October & 17.2 & -0.5 & & 18.2 & 1.8 \\
November & 12.6 & 0.4 & & 15.5 & 3.4 \\
December & 12.1 & 0.6 & 15.7 & 7.4 \\
Mean & 11.9 & 0.0 & 13.5 & 3.9 \\
\hline
\end{tabular}

solar irradiation resource over La Réunion and its variability respectively. Within a year, the solar resource is highly dependent on the topography and correlated to weather patterns prevailing over the island. The solar radiation variability is related to large scale weather seasonal variability but is also sensitive to super imposed local dynamical and thermodynamical atmospheric con ditions (i.e. wind ward, sea land breeze, vertical instability) induced by orographic patterns.

To test the performance of the downscaling methodology adopted in this study, leave one out kriging was performed on $\mathrm{GHI}_{\mathrm{D}}$ for each of the 32 ground stations and the process was then repeated for all months. In each case, the error between the interpolated value and the ground measurement at the removed station was computed. Fig. 12 provides a comparative analysis of the RMSE for each month resulting from the leave one out kriging process and the satellite based $\mathrm{GHI}$ data, $\mathrm{GHI}_{\mathrm{CMSAF}}$, with respect to ground measurements. The straight line represents the case when the two techniques yield the same error. It can be observed that for most months, the proposed methodology decreases the error in the GHI estimates by up to $5 \mathrm{~kW} / \mathrm{m}^{2}$ compared to the satellite based data. In May, June and July, the error in $\mathrm{GHI}_{\mathrm{CMSAF}}$ was already low, of the order of $12 \mathrm{~kW} / \mathrm{m}^{2}$, and no improvement was noted. On average, the proposed methodology improved the RMSE by about $15 \%$. It is also observed that the maximum RMSE of the proposed model is limited to $20 \mathrm{~kW} / \mathrm{m}^{2}$ for all months except October, when it rises to $25 \mathrm{~kW} / \mathrm{m}^{2}$. Nevertheless, this maximum error for the proposed methodolgy is still three times less than that observed by Antonanzas Torres et al. [30] in their study.

Fig. 13 shows the monthly relative difference between the GHI estimates from the leave one out kriging process and the ground measurement at the 32 stations. The same colour code as for Fig. 5 was used here. It is noted that in most of the 384 individual cases, the differences are relatively low, of the order of $10 \%$ or less. In the month of January, for instance, only 2 stations show a difference greater than 20\% in Fig. 13 as compared to 6 stations in Fig. 5. It is also important to highlight that although the errors at three sta tions mentioned in Section 2.4 (Bellecombe and Sainte Rose in the South East and Petite France in the North West) are still significant for all months, they are generally less than the values reported in Fig. 5. It is observed that the two stations in the South East are isolated due to their location in the vicinity of the volcano. Consequently, using readings from stations that are further away to extrapolate GHI data at these locations through kriging is inade quate. The validation approach used can therefore also indicate areas where implementation of future ground stations would be most warranted. On the other hand, Petite France has four other 
ground stations in its surroundings. But, as explained in Section 2.4, the spatial variability of GHI in this region depends to a large extent on the cloud cover in addition to the topography.

Table 2 compares the percentage RMSE and mean bias error (MBE) for each month between the maps output by the proposed methodology and the CMSAF derived maps with respect to the ground based data. It is noted that both the RMSE and MBE have decreased due to the application of the leave one out kriging process for all months. Nevertheless, most significant error re ductions are observed in summer months.

\section{Conclusion}

In this work, a DEM based model that takes into consideration the effects of topographic features on solar irradiance is used to downscale $5 \mathrm{~km} \times 5 \mathrm{~km}$ gridded CMSAF derived GHI maps for Reunion Island to a much finer resolution of $250 \mathrm{~m} \times 250 \mathrm{~m}$. This model presents a simple methodology to obtain high resolution spatial and temporal solar irradiance maps for regions with overly complex topography like young volcanic islands. It also provides a means to generate reliable GHI data in remote areas that are difficult to access. Reunion Island provides an appropriate case study as it is targeting energy autonomy by 2030 , with the bulk of electrical power expected to come from renewable energy tech nologies, principally solar PV. The extremely complex topography of the volcanic island gives rise to strong local gradients in solar irradiance that cannot be captured by the sparse radiometric network.

Highly accurate insolation models are difficult to implement due to the intricate interactions that occur among the atmosphere, topography, surface type and plant canopies. As such, efforts should be directed towards improving the accuracy of existing estimates, which was the case in this study. The proposed approach is convenient and appealing as its input data requirements are readily available. Nevertheless, there is scope for enhancement. The model does not consider the impact of multiple reflection and albedo on insolation. Multiple reflections between highly reflective ground surfaces and clouds can have a major influence on the GHI partic ularly near the peak of cirques which are sometimes covered with snow during winter months. The anisotropy of the multiple re flections could also be investigated. In addition, the effect of canopy cover has not been incorporated in the proposed methodology. The influence of heterogeneous canopy on ground insolation as well as its interaction with topography can be integrated in the model.

\section{References}

[1] REN21, Renewables 2016-Global Status Report, 2016. Paris.

[2] B. Del Fabbro, A. Valentincic, A.F. Gubina, An adequate required rate of return for grid-connected PV systems, Sol. Energy 132 (2016) 7383.

[3] C.A. Gueymard, S.M. Wilcox, Assessment of spatial and temporal variability in the US solar resource from radiometric measurements and predictions from models using ground-based or satellite data, Sol. Energy 85 (2011) 10681084

[4] S. Moreno-Tejeraa, M.A. Silva-Pйrez, I. Lillo-Bravo, L. Ramнrez-Santigosa, Solar resource assessment in Seville, Spain. Statistical characterisation of solar radiation at different time resolutions, Sol. Energy 132 (2016) 430441.

[5] J.A. Ruiz-Arias, J. Tovar-Pescador, D. Pozo-Vøzquez, H. Alsamamra, A comparative analysis of DEM-based models to estimate the solar radiation in mountainous terrain, Int. J. Geogr. Inf. Sci. 23 (2009) 10491076.

[6] L.M. Ayompe, A. Duffy, An assessment of the energy generation potential of photovoltaic systems in Cameroon using satellite-derived solar radiation datasets, Sustain. Energy Technol. Assess. 7 (2014) 257264.

[7] R.A. Escobar, C. Cortŭs, A. Pino, E.B. Pereira, F.R. Martins, J.M. Cardemil, Solar energy resource assessment in Chile: satellite estimation and ground station measurements, Renew. Energy 71 (2014) 324332.

[8] F.R. Martins, E.B. Pereira, S.L. Abreu, Satellite-derived solar resource maps for Brazil under SWERA project, Sol. Energy 81 (2007) 517528.

[9] B. Pillot, M. Muselli, P. Poggi, J.B. Dias, Satellite-based assessment and in situ validation of solar irradiation maps in the Republic of Djibouti, Sol. Energy 120 (2015) 603619.

[10] J. Polo, A. Bernardos, A.A. Navarro, C.M. Fernandez-Peruchena, L. Ramrrez, M.V. Guisado, S. Marthnez, Solar resources and power potential mapping in Vietnam using satellite-derived and GIS-based information, Energy Convers. Manag. 98 (2015) 348358.

[11] S. St kler, C. Schillings, B. Kraas, Solar resource assessment study for Pakistan, Renew. Sustain. Energy Rev. 58 (2016) 11841188.

[12] R. Dubayah, P.M. Rich, Topographic solar radiation models for GIS, Int. J. Geogr. Inf. Syst. 9 (1995) 405419.

[13] R.G. Gillespie, D.A. Clague, Encyclopedia of Islands (No. 2), Univ of California Press, 2009.

[14] Bilan EDF, Prŭvisionnel Pluriannuel, investissements en production, Paris, 2016.

[15] J. Badosa, M. Haeffelin, H. Chepfer, Scales of spatial and temporal variation of solar irradiance on Reunion tropical island, Sol. Energy 88 (2013) 4256.

[16] P. Fu, P.M. Rich, The Solar Analyst 1.0, User Manual, Vermont, KS, 2000.

[17] I.D. Moore, T.W. Norton, J.E. Williams, Modelling environmental heterogeneity in forested landscapes, J. Hydrol. 150 (1993) 717747.

[18] J.A. Ruiz-Arias, T. Cebecauer, J. Tovar-Pescador, M. Suri, Spatial disaggregation of satellite-derived irradiance using a high-resolution digital elevation model, Sol. Energy 84 (2010) 16441657.

[19] B. Pillot, M. Muselli, P. Poggi, P. Haurant, I. Hared, The first disaggregated solar atlas of Djibouti: A decision-making tool for solar systems integration in the energy scheme, Renew. Energy 57 (2013) 5769.

[20] J.L. Bosch, F.J. Batlles, L. Zarzalejo, G. Lypez, Solar resources estimation combining digital terrain models and satellite images techniques, Renew. Energy 35 (2010) 28532861.

[21] P. Haurant, M. Muselli, B. Pillot, P. Oberti, Disaggregation of satellite derived irradiance maps: Evaluation of the process and application to Corsica, Sol. Energy 86 (2012) 31683182.

[22] G. Jumaux, H. Quetelard, D. Roy, Atlas climatique de la Rŭunion, 2011.

[23] J.-F. Oehler, J.-F. Lŭnat, P. Labazuy, Growth and collapse of the Reunion Island volcanoes, Bull. Volcanol. 70 (2008) 717742.

[24] S. Selosse, O. Ricci, S. Garabedian, N. Maïzi, Reunion Island energy autonomy objective by 2030, EcoMod2014, International Conference on Economic Modeling (2014). Bali, Indonesia.

[25] T. Huld, R. Mbller, A. Gambardellaa, A new solar radiation database for estimating PV performance in Europe and Africa, Sol. Energy 86 (2012) 18031815.

[26] M. Súri, J. Remund, T. Cebecauer, D. Dumortier, L. Wald, T. Huld, P. Blanc, First Steps in the Cross-Comparison of Solar Resource Spatial Products in Europe, in: Proc. EUROSUN 2008, Potugal, Lisbon, 2008.

[27] J.S. Bojanowski, A. Vrieling, A.K. Skidmore, Jedrzej S. Bojanowski, Anton Vrieling, Andrew K. Skidmore, A comparison of data sources for creating a long-term time series of daily gridded solar radiation for Europe, Sol. Energy 99 (2014) 152171.

[28] R. Perez, R. Seals, A. Zelenka, Comparing satellite remote sensing and ground network measurements for the production of site/time specific irradiance data, Sol. Energy 60 (1997) 8996.

[29] P. Redweik, C. Catita, M. Brito, Solar energy potential on roofs and facades in an urban landscape, Sol. Energy 97 (2013) 332341.

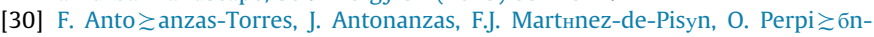
Lamigueiro, M. Alia-Martinez, Downscaling of solar irradiation from satellite estimates, Proj. Manag. Eng. (2015) 197205.

[31] J.E. Hay, D.C. McKay, Estimating solar irradiance on inclined surfaces: a review and assessment of methodologies, Int. J. Sol. Energy 3 (1985) 203240.

[32] D.A. Chwieduk, Recommendation on modelling of solar energy incident on a building envelope, Renew. Energy 34 (2009) 736741.

[33] J.E. Hay, Solar energy system design: The impact of mesocale variations in solar radiation, Atmos. Ocean 21 (1983) 138157.

[34] K. Zakšek, K. Oštir, Z Kokalj, Sky-view factor as a relief visualization technique, Sky-View Fact. Reli. Vis. Tech. 3 (2011) 398415

[35] R. Webster, M.A. Oliver, Geostatics for Environmental Scientist, John Wiley and Sons, Chichester, England, 2004.

[36] C. Prudhomme, D.W. Reed, Mapping extreme rainfall in a mountainous region using geostatistical techniques: a case study in Scotland, Int. J. Climatol. 19 (1999) 13371356. 